American Journal of Applied Sciences 1 (4): 266-272, 2004

ISSN 1546-9239

(C) Science Publications, 2004

\title{
Duration Modeling in Undergraduate Econometrics Curriculum via Excel
}

\author{
Ismail $\mathrm{H}$. Genc \\ College of Business and Economics, College of Science \\ University of Idaho, Moscow, Idaho 83844-3178
}

\begin{abstract}
The main goal of an Econometrics course is to prepare students for more advanced levels of study and make them able to cope with the empirical problems they are likely to face. In recent years, there has been a tendency to purge merely theoretical topics from the econometric textbooks by including only time honored methods. Survival analysis, however, has so far failed to attract the attention of textbook writers. I conjecture that the general perception of the issue as an advanced topic as well as software barriers have led to this attitude. In this study, I work out an Excel file to outline the fundamental concepts of duration analysis at an introductory level. The file so generated may also be used by practitioners in appropriate cases with minimal learning cost. As such, I hope to dissipate the myth of difficulty associated with this subject matter.
\end{abstract}

Key words: JEL Classification code(s): A23, C41, C88

\section{INTRODUCTION}

The undergraduate education aspires to equip students with tools most needed to tackle real life situations that students are likely to face upon assuming positions in the post-graduate world. Arguably, one of the most application oriented courses in economics and business is Econometrics. Realizing the need to provide students with the techniques they will make use of at work, Econometrics textbooks try to tailor themselves to such a challenge. They mainly try to avoid being an encyclopedia of Econometrics, which may include any topic under the sun ever discussed in academic circles, but rather concentrate on those select issues based upon the criteria indicated above.

Ironically, one of these topics, the duration analysis, has so far failed to find its way to undergraduate Econometrics curricula. My survey of several undergraduate textbooks supports this observation. As ${ }^{[[]}$rightfully complain even though there are so many journal articles both in the theoretical as well as an empirical sense on this issue, any course dealing with the duration analysis is considered beyond the reach of the undergraduate students and even for graduate students, it is postponed to advanced levels of study.

I contend, however, that a starter on the topic should (or maybe "could") be included in the undergraduate curriculum and it is actually quite possible to impart the fundamental ideas of duration analysis even with a minimal understanding of statistics and Econometrics. Nevertheless, one should not ignore the fact that the instructors are under heavy pressure regarding the choice of topics given a fixed timetable, i.e. A semester or so. Needless to say, this might the one of the major reasons why this topic is mainly left out. Another reason perhaps is the lack of a proper treatment of the topic in the texts.

In this study, I generate a simple Excel file to introduce duration analysis in an easy to understand environment. Furthermore, as the concise literature review below will attest to the fact that the applicability of the duration analysis in business and economics as well as in many other social sciences, even practitioners may benefit from the discussion and the technique presented here if the case happens to be suitable for such an analysis with minimal learning cost. This study is also intended to address to the needs of professionals in the field, but with no prior experience in duration analysis since it is an easy treatment of the topic.

Duration analysis is the study of the length of time it takes economic agents to leave a specific state, i.e. It is the "time to event" study. The duration analysis has found its applications in many fields. However, a common name for it is yet to come. The naming convenience is more of a reflection of its application context. Some of the possible names may be 'event history analysis' (sociology), 'failure time analysis' or 'reliability analysis' (engineering), 'duration analysis,' 'survival analysis,' 'transition analysis' (economics) ${ }^{[2]}$. I will make use of any one of these concepts interchangeably in this study, hoping to establish the link between various fields of study which use the analysis.

Although the survival analysis in population studies goes back to pre1700s $\mathrm{s}^{[3]}$, the econometric analysis of the duration of events (processes in transition) began in $1970 \mathrm{~s}^{[4,5]}$. Examples of duration analysis in business and economics cover a wide variety of topics. But by far, the largest application has been in labor economics. The book by ${ }^{[4]}$ makes use of labor economics examples throughout. I will cite a few studies in various branches of economics and business to convey the possible scope of this tool. Naturally this is not meant to be an exhaustive list ${ }^{[4]}$.

Is the most comprehensive Econometrics book on the issue. ${ }^{[6,7]}$ are other sources for a thorough analysis of duration methods ${ }^{[6]}$. Provides a relatively nontechnical survey of the topic where the duration of 
marriages, spacing of births, time to adoption of new technologies, time between trades in financial markets, product durability, duration of wars, time in office for congressmen and other elected officials, length of stay in graduate school are mentioned as actual and potential areas of application of these models. Also the survey by ${ }^{[8]}$ provides an overview of many methods available in the literature.

Other examples for the duration of employment related decisions such as unemployment benefits, strike durations and on-the-job training programs and labor market participation, are also discussed ${ }^{[9-23]}$.

Population and migration economics have extensively used the duration analysis to study such topics as the duration of marriages, migration time lengths, time until the birth of a child as well as issues surrounding family breakdowns. One can refer to ${ }^{[24-27]}$.

[28-30] represent various applications in the marketing and consumer economics fields ${ }^{[31]}$. Apply a competing risks model with unobserved heterogeneity to study households' repeat-purchase and switching patterns among brands ${ }^{[32]}$. Study the impact of promotion on the duration between purchases ${ }^{[33]}$. Can be mentioned as an example in the industrial organization field where they study the duration of a patent. What motivates someone to take a major investment decision after a lull period is studied in ${ }^{\text {[34] }}$ Determinants of retention in graduate level economics programs is studied in ${ }^{[35]}$.

Applications in macroeconomics and finance are found in ${ }^{[36-41]}$. Another widely applied field is political economy where the duration of tenure in a political office $^{[42-44]}$ or that of wars ${ }^{[45]}$ are studied. Other notable economic applications of various methods in survival analysis are ${ }^{[5,46-48]}$.

To do justice to non-economics fields where perhaps these techniques have found larger audiences, the reader is referred to ${ }^{[7]}$ for Sociology, ${ }^{[1,49]}$ for Biometrics and Medical Sciences and ${ }^{[50]}$ for Statistics applications of the duration analysis.

A Brief Introduction to Survival Analysis: The survival analysis deals with the length of time it takes for something to happen. For example, how long it takes for someone to leave the state (spell) of unemployment, or to leave the first job, or how long it takes for a machine to fail to operate? A more interesting issue is the impact of a certain treatment on the length of time it takes for an event to happen. To illustrate the point we can mention the survival (retention) times of those employees in jobs with a day care center versus those in jobs without a day care center; or in jobs where childcare is provided and jobs where it is not.

The basic difference between the traditional macroeconomic processes and the duration analysis is that the former is assumed to be complete while the latter is not necessarily completed by the time data are collected. This point calls into question the validity of inferences based on the assumption of completeness because in real life economic agents do not necessarily make their decisions at the same time point data are collected. Moreover, some of the agents may have dropped out of the observation process for various reasons, a case which is called Censoring. Ignoring censoring could potentially lead to unreliable results ${ }^{[51]}$. For censored agents all we know is that they had survived until the last time we took data about them. This is called right censoring. For more on this issue, the reader is referred to the aforementioned references. A related concept in duration analysis is the hazard (rate) function, h. Simply put, hazard rate is the probability of an event happening immediately after period t once it is known that it has not taken place until time t. For example, it is the probability of someone finding a job today (exiting the current state of unemployment today) given that he has not been able to find one so far. Statistically, the hazard function of an event can be written as:

$h(t)=\lim _{\Delta t \rightarrow 0} \frac{P(t \leq T<t+\Delta t \backslash T \geq t)}{\Delta t}$

where, D represents an incremental change. The only difference between the hazard function and a probability density function, pdf, is the conditionality imposed by the hazard function because pdf measures the probability of someone finding a job today irrespective of how long the person might have been in the job market.

On a related note, notice that if we interpret the hazard function as the risk of an event occurring at any time once time $t$ is reached, the inverse of the hazard function, $1 / \mathrm{h}(\mathrm{t})$, can be interpreted as the expected length of time until the event occurs assuming $h(t)$ remains constant ${ }^{[2]}$.

The statistical representation of the survival function is:

$S(t)=P(T>t)=1-F(t)$

where, $\mathrm{F}$ stands for the cumulative distribution function, pdf. One can easily relate the two equations to one another via:

$h(t)=\frac{f(t)}{S(t)}$

where, $\mathrm{f}$ is a pdf. It is clear that there is a well-defined road map among $\mathrm{f}, \mathrm{h}, \mathrm{F}$ and $\mathrm{S}$. Thus, analyses on a subgroup of them can be transferred to others through statistical methods, which means that discussing the hazard of a phenomenon will readily yield its characteristics in terms of its survival and vice versa.

There are parametric as well as non-parametric methods of survival analysis. The non-parametric analysis is handled through the so-called life tables. It is a ratio analysis whose goal is to find/describe the proportion of agents surviving at various time intervals. Life tables are mostly drawn for two different groups (or potentially for more groups), one which has gone through some treatment (treatment group) while the other (the control group) which has not. The basic idea 
is to see the impact of treatment on the survivorship of the subjects under study. Interpreted this way, different life tables for different categories of economic agents yield comparably similar results to the parametric analysis without actually running one such analysis.

If the impact of several independent variables, called covariates in the duration literature, need to be detected, the parametric counterpart of life tables can be employed. But that requires quite a few assumptions to be made by the researcher regarding the shape of the distribution of the survival. Although this method may be more akin to the popular regression methods, one should not forget that the censoring of the data could make parametric methods subject to a lot of personal preferences on the part of the researcher, which may lead to a variety of results depending on the parametric distribution chosen. That is why; life tables for various groups can be used with minimal loss of qualitative generality for inference purposes. In what follows, a simple method to obtain life tables is discussed.

Life Tables for Survival Analysis: As mentioned before, the main reason duration analysis is left out of the undergraduate curriculum is the supposed difficulty associated with the method in question. Obviously, the cost of learning software might also play a role in this outcome. But I believe that this important tool could easily be incorporated into the undergraduate curriculum without much cost as long as students are capable of using Excel, which is almost given.

A hypothetical data set was generated and thereafter the basics of survival analysis via the life tables are discussed.

Suppose we follow up 13 people in the job market for 15 months. In reality, this is a very small data set and all statistical troubles with small samples should come to mind when interpreting findings from such a data set. However, for us, it serves the purpose of illustrating our points. We are interested in the time length they stay in the job market. All individuals are high school graduates. However, some of them took college level pre-business classes (Treatment Group) before entering the job market while others did not (Control Group). The treatment group earned a prebusiness certification as a result. We would like to see the survival of both groups individually and in a comparative sense. The comparison of survival in the job market for the high school graduates will give us the partial impact of the pre-business classes (certificate) on finding a job. The data set is shown in Fig. 1.

In the data set, ID is a personal identifier such as Person 1, Person 2. And it refers to the "individual," that is the subject that is followed up throughout a given state to see if he or she has exited the current state. In our case, the individual may or may not leave the current state of being unemployed. If he or she has already left the state of unemployment, we code 1 under the column Unemployed for him or her. If the individual has not left the given state after our data collection period comes to an end, in this example that is 15 months, he or she is coded 0 under the same column. Thus, Unemployed is binary status indicator variable. The person who has left the job market is said to have "exited" the state.
Another dummy variable is PreBus, which takes on a value of 1 for the subjects who took the college level pre-business classes (Treatment Group) and 0 for those who did not (Control Group). Duration of the data set refers to the length of time in months a person has been/stayed in the job market.

There are 8 people in our data set who fall in the control group and 5 in the treatment category. Of these 13 people, all but one, ID 13, has exited the state of unemployment. Thus, the individual 13 is censored in our example. The minimum stay in the job market is $1 \mathrm{a}$ month while the maximum surpasses 15 months. On the average, people stay in the job market 6.69 months with a standard deviation of 5.38 months. The median duration is 5 months.

To generate life tables we divide the observation period into 10 equal subperiods of 1.5 months. The choice of a range, $r$, is arbitrary and basically depends on the interests of the researcher. We re-present the data pertaining to the two sub-groups in Fig. 2 for the control group and in Fig. 3 for the treatment group.

\begin{tabular}{|c|c|c|c|c|c|}
\hline & A & B & C & D & E \\
\hline 1 & ID & PreBus & Unemployt & Duration & \\
\hline 2 & 1 & 1 & 1 & 1 & \\
\hline 3 & 2 & 0 & 1 & 1 & \\
\hline 4 & 3 & 1 & 1 & 2 & \\
\hline 5 & 4 & 1 & 1 & 2 & \\
\hline 6 & 5 & 0 & 1 & 2 & \\
\hline 7 & 6 & 0 & 1 & 4 & \\
\hline 8 & 7 & 1 & 1 & 5 & \\
\hline 9 & 8 & 0 & 1 & 8 & \\
\hline 10 & 9 & 0 & 1 & 8 & \\
\hline 11 & 10 & 0 & 1 & 10 & \\
\hline 12 & 11 & 1 & 1 & 14 & \\
\hline 13 & 12 & 0 & 1 & 15 & \\
\hline 14 & 13 & 0 & 0 & 15 & \\
\hline 15 & & & & & \\
\hline
\end{tabular}

Fig. 1: Data Set

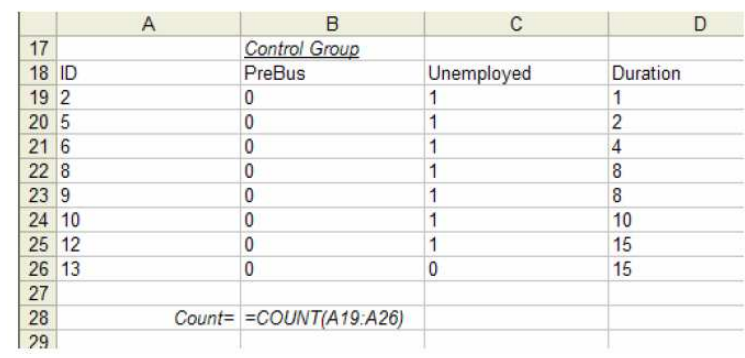

Fig. 2: Control Group Data

\begin{tabular}{|c|c|c|c|c|c|}
\hline & $\mathrm{A}$ & $\mathrm{B}$ & C & D & $\mathrm{E}$ \\
\hline 46 & & \multicolumn{2}{|c|}{ Treatment Group } & & \\
\hline 47 & ID & PreBus & Unemployed & \multicolumn{2}{|c|}{ Duration } \\
\hline 48 & 1 & 1 & 1 & 1 & \\
\hline 49 & 3 & 1 & 1 & 2 & \\
\hline 50 & 4 & 1 & 1 & 2 & \\
\hline 51 & 7 & 1 & 1 & 5 & \\
\hline 52 & 11 & 1 & 1 & 14 & \\
\hline 53 & & & & & \\
\hline 54 & Count $=$ & 5 & & & \\
\hline
\end{tabular}

Fig. 3: Treatment Group Data 


\begin{tabular}{|c|c|c|c|c|c|c|c|c|c|}
\hline & A & B & C & D & E & $\mathrm{F}$ & G & $\mathrm{H}$ & 1 \\
\hline 32 & R0 & R1 & Entered & Censored & Dropped & Proportion:q & Proportion:p & $\mathbf{P}$ & 1.P \\
\hline 33 & $=0$ & $=A 33+1.5$ & $=\mathrm{B} 28$ & 0 & 1 & $=\mathrm{E} 33 /(\mathrm{C} 33-\mathrm{D} 33)$ & $=1-\mathrm{F} 33$ & 1 & $=1-\mathrm{H} 33$ \\
\hline 34 & $=\mathrm{B} 33$ & $=A 34+1.5$ & $=\mathrm{C} 33-\mathrm{E} 33$ & 0 & 1 & $=E 34 /(C 34-D 34)$ & $=1-\mathrm{F} 34$ & $=\mathrm{G} 33^{*} \mathrm{H} 33$ & $=1-\mathrm{H} 34$ \\
\hline 35 & $=\mathrm{B} 34$ & $=A 35+1.5$ & $=$ C $34-E 34$ & 0 & 1 & $=\mathrm{E} 35 /(\mathrm{C} 35-\mathrm{D} 35)$ & $=1-\mathrm{F} 35$ & $=\mathrm{G} 34^{*} \mathrm{H} 34$ & $=1-\mathrm{H} 35$ \\
\hline 36 & $=\mathrm{B} 35$ & $=A 36+1.5$ & $=\mathrm{C} 35-\mathrm{E} 35$ & 0 & 0 & $=\mathrm{E} 36 /(\mathrm{C} 36-\mathrm{D} 36)$ & $=1-\mathrm{F} 36$ & $=\mathrm{G} 35^{*} \mathrm{H} 35$ & $=1-\mathrm{H} 36$ \\
\hline 37 & $=\mathrm{B} 36$ & $=A 37+1.5$ & $=\mathrm{C} 36-\mathrm{E} 36$ & 0 & 0 & $=\mathrm{E} 37 /(\mathrm{C} 37-\mathrm{D} 37)$ & $=1-\mathrm{F} 37$ & $=\mathrm{G} 36^{*} \mathrm{H} 36$ & $=1-\mathrm{H} 37$ \\
\hline 38 & $=\mathrm{B} 37$ & $=A 38+1.5$ & $=\mathrm{C} 37-\mathrm{E} 37$ & 0 & 2 & $=E 38 /(C 38-D 38)$ & $=1-\mathrm{F} 38$ & $=\mathrm{G} 37^{*} \mathrm{H} 37$ & $=1-\mathrm{H} 38$ \\
\hline 39 & $=\mathrm{B} 38$ & $=A 39+1.5$ & $=\mathrm{C} 38-\mathrm{E} 38$ & 0 & 1 & $=\mathrm{E} 39 /(\mathrm{C} 39-\mathrm{D} 39)$ & $=1-\mathrm{F} 39$ & $=\mathrm{G} 38^{*} \mathrm{H} 38$ & $=1-\mathrm{H} 39$ \\
\hline 40 & $=\mathrm{B} 39$ & $=\mathrm{A} 40+1.5$ & $=$ C $39-E 39$ & 0 & 0 & $=\mathrm{E} 40 /(\mathrm{C} 40-\mathrm{D} 40)$ & $=1-\mathrm{F} 40$ & $=\mathrm{G} 39^{*} \mathrm{H} 39$ & $=1-\mathrm{H} 40$ \\
\hline 41 & $=\mathrm{B} 40$ & $=\mathrm{A} 41+1.5$ & $=C 40-E 40$ & 0 & 0 & $=\mathrm{E} 41 /(\mathrm{C} 41-\mathrm{D} 41)$ & $=1-\mathrm{F} 41$ & $=\mathrm{G} 40 * \mathrm{H} 40$ & $=1-\mathrm{H} 41$ \\
\hline 42 & $=\mathrm{B} 41$ & $=A 42+1.5$ & $=\mathrm{C} 41-\mathrm{E} 41$ & 1 & 2 & $=\mathrm{E} 42 /(\mathrm{C} 42-\mathrm{D} 42)$ & $=1-\mathrm{F} 42$ & $=\mathrm{G} 41^{*} \mathrm{H} 41$ & $=1-\mathrm{H} 42$ \\
\hline 43 & & & & & & & & & \\
\hline
\end{tabular}

Fig. 4: Calculation of the Survival Function for the Control Group

\begin{tabular}{|c|c|c|c|c|c|c|c|c|c|c|}
\hline & A & B & C & D & $E$ & $\mathrm{~F}$ & G & $\mathrm{H}$ & I & \\
\hline 31 & \multicolumn{2}{|c|}{ Interval } & & & \multicolumn{2}{|c|}{ Control Group } & & & & \\
\hline 32 & Ro & R1 & Entere! & Cens & Dropf & Proportio & Proport & & 1-P & \\
\hline 33 & 0 & 1.5 & 8 & 0 & 1 & 0.125 & 0.875 & 1 & 0 & \\
\hline 34 & 1.5 & 3 & 7 & 0 & 1 & 0.142857 & 0.8571 & 0.875 & 0.125 & \\
\hline 35 & 3 & 4.5 & 6 & 0 & 1 & 0.166667 & $0.8333^{\prime}$ & 0.75 & 0.25 & \\
\hline 36 & 4.5 & 6 & 5 & 0 & 0 & 0 & 1 & 0.625 & 0.375 & \\
\hline 37 & 6 & 7.5 & 5 & 0 & 0 & 0 & $1^{7}$ & 0.625 & 0.375 & \\
\hline 38 & 7.5 & 9 & 5 & 0 & 2 & 0.4 & 0.6 & 0.625 & 0.375 & \\
\hline 39 & 9 & 10.5 & 3 & 0 & 1 & 0.333333 & 0.6667 & 0.375 & 0.625 & \\
\hline 40 & 10.5 & 12 & 2 & 0 & 0 & 0 & 1 & 0.25 & 0.75 & \\
\hline 41 & 12 & 13.5 & 2 & 0 & 0 & 0 & 1 & 0.25 & 0.75 & \\
\hline 42 & 13.5 & 15 & 2 & 1 & 2 & 2 & -1 & 0.25 & 0.75 & \\
\hline 43 & & & & & & & & & & \\
\hline
\end{tabular}

Fig. 5: Numerical Values of Survivorship Calculation of the Control Group

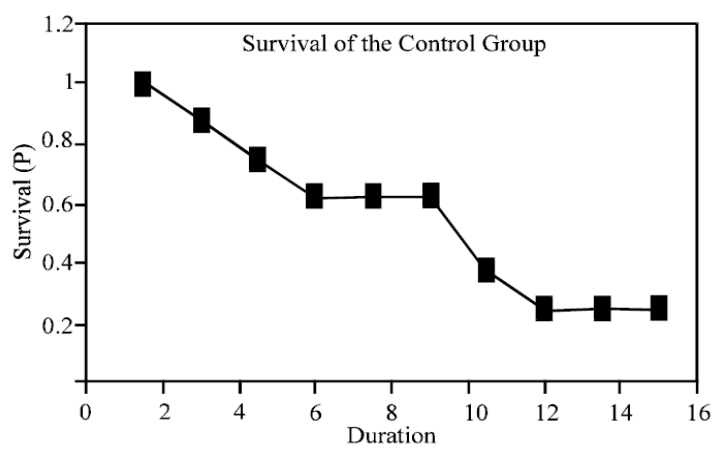

Fig. 6: Survival Chart of the Control Group

Concentrating on the control group first, we carry out the calculations as in Fig. 4. R0 and R1 in the figure refer to the beginning and the end of the sub period, respectively. Thus, $\mathrm{r}=\mathrm{R} 1-\mathrm{R} 0$. Notice that the beginning of the very first sub period is zero while its end is dictated by the researcher, in our case, $r=1.5$ months. The rest follows the suit. The column labeled Entered gives the total number of people still in the given state (process), that is, those who are still unemployed. Initially, everybody is in the unemployment state, but in the subsequent sub periods, this number is reduced as people exit the state as shown in the column titled Dropped. If a person is censored, a 1 is coded in the Censored column, otherwise a 0. Only the last observation is censored in this category because this person has not left the job market by the time our observation (data collection) period came to an end.
Proportion: q represents the ratio of those who could NOT survive the sub period. This is called the Failure Rate. It is calculated as the ratio of those who completed (those who could NOT survive) the sub period to all those who entered it less censored ones. Another proportion concept, i.e. Proportion: $p$ gives the ratio of those who could survive the sub period. It is calculated as 1-q. This is called the Survival Rate. However, what we mean by survival, as in equation 2 , is given by the column titled $\mathrm{P}$, which is called the Cumulative Survival Function. Observe that the first value in this column is 1 . This is simply a convenient assumption to get the process going. It means that initially all individuals would have a survival of $100 \%$. The cumulative survival function in each sub period is calculated as:

$P_{j}=p_{j-1} P_{j-1}$

where, $\mathrm{j}$ represents the current sub period. For the sake of completeness, we present in the figure what is called the Cumulative Failure Rate, 1-P. It has a corresponding interpretation of the Cumulative Survival Rate. The numerical values of these calculations are presented in Fig. 5.

Figure 6 depicts a survival chart for the control group, which shows the cumulative survival rate (column labeled P) against the duration (column labeled $\mathrm{R} 1)$. The choice between R0 and R1 is not standard, but most of the literature prefers R1 to R0. Alternatively, the midpoint between R1 and R0 could be used. The main trick at this stage is to interpret the graph, which is nothing but to correctly read the numbers off of it. 
American J. Appl. Sci., 1 (4): 266-272, 2004

\begin{tabular}{|c|c|c|c|c|c|c|c|c|c|}
\hline & A & $B$ & C & D & $E$ & $F$ & G & $\mathrm{H}$ & 1 \\
\hline 56 & Interval & & & & Treatment & & & & \\
\hline 57 & R0 & R1 & Entered & Censored & Dropped & Proportion:q & Proportion:p & $\mathbf{P}$ & 1-P \\
\hline 58 & $=0$ & $=A 58+1.5$ & $=\mathrm{B} 54$ & 0 & 1 & $=\mathrm{E} 58 /(\mathrm{C} 58-\mathrm{D} 58)$ & $=1-\mathrm{F} 58$ & 1 & $=1-\mathrm{H} 58$ \\
\hline 59 & $=\mathrm{B} 58$ & $=\mathrm{A} 59+1.5$ & $=C 58-E 58$ & 0 & 2 & $=\mathrm{E} 59 /(\mathrm{C} 59-\mathrm{D} 59)$ & $=1-\mathrm{F} 59$ & $=\mathrm{G} 58^{*} \mathrm{H} 58$ & $=1-\mathrm{H} 59$ \\
\hline 60 & $=\mathrm{B} 59$ & $=A 60+1.5$ & $=C 59-E 59$ & 0 & 0 & $=\mathrm{E} 60 /(\mathrm{C} 60-\mathrm{D} 60)$ & $=1-\mathrm{F} 60$ & $=\mathrm{G} 59^{*} \mathrm{H} 59$ & $=1-\mathrm{H} 60$ \\
\hline 61 & $=\mathrm{B} 60$ & $=\mathrm{A} 61+1.5$ & $=\mathrm{C} 60-\mathrm{E} 60$ & 0 & 1 & $=\mathrm{E} 61 /(\mathrm{C} 61-\mathrm{D} 61)$ & $=1-\mathrm{F} 61$ & $=\mathrm{G} 60^{*} \mathrm{H} 60$ & $=1-\mathrm{H} 61$ \\
\hline 62 & $=\mathrm{B} 61$ & $=A 62+1.5$ & $=\mathrm{C} 61-\mathrm{E} 61$ & 0 & 0 & $=\mathrm{E} 62 /(\mathrm{C} 62-\mathrm{D} 62)$ & $=1-F 62$ & $=\mathrm{G} 61^{*} \mathrm{H} 61$ & $=1-\mathrm{H} 62$ \\
\hline 63 & $=\mathrm{B} 62$ & $=A 63+1.5$ & $=\mathrm{C} 62-\mathrm{E} 62$ & 0 & 0 & $=E 63 /(C 63-D 63)$ & $=1-\mathrm{F} 63$ & $=\mathrm{G} 62^{*} \mathrm{H} 62$ & $=1-\mathrm{H} 63$ \\
\hline 64 & $=\mathrm{B} 63$ & $=\mathrm{A} 64+1.5$ & $=\mathrm{C} 63-\mathrm{E} 63$ & 0 & 0 & $=\mathrm{E} 64 /(\mathrm{C} 64-\mathrm{D} 64)$ & $=1-\mathrm{F} 64$ & $=\mathrm{G} 63^{*} \mathrm{H} 63$ & $=1-\mathrm{H} 64$ \\
\hline 65 & $=\mathrm{B} 64$ & $=A 65+1.5$ & $=C 64-E 64$ & 0 & 0 & $=\mathrm{E} 65 /(\mathrm{C} 65-\mathrm{D} 65)$ & $=1-F 65$ & $=\mathrm{G} 64^{*} \mathrm{H} 64$ & $=1-\mathrm{H} 65$ \\
\hline 66 & $=\mathrm{B} 65$ & $=A 66+1.5$ & $=\mathrm{C} 65-\mathrm{E} 65$ & 0 & 0 & $=\mathrm{E} 66 /(\mathrm{C} 66-\mathrm{D} 66)$ & $=1-\mathrm{F} 66$ & $=\mathrm{G} 65^{*} \mathrm{H} 65$ & $=1-\mathrm{H} 66$ \\
\hline 67 & $=\mathrm{B} 66$ & $=\mathrm{A} 67+1.5$ & $=\mathrm{C} 66-\mathrm{E} 66$ & 0 & 1 & $=\mathrm{E} 67 /(\mathrm{C} 67-\mathrm{D} 67)$ & $=1-\mathrm{F} 67$ & $=\mathrm{G} 66^{*} \mathrm{H} 66$ & $=1-\mathrm{H} 67$ \\
\hline
\end{tabular}

Fig. 7: Calculation of the Survival Function for the Treatment Group

\begin{tabular}{|c|c|c|c|c|c|c|c|c|c|c|}
\hline & A & B & C & D & $E$ & $\mathrm{~F}$ & G & $\mathrm{H}$ & 1 & $\mathrm{~J}$ \\
\hline 56 & Interval & & & & Treatm & ent Group & & & & \\
\hline 57 & R0 & R1 & Entered & Cens & DropF & Proportio & Proport F & & 1-P & \\
\hline 58 & 0 & 1.5 & 5 & 0 & 1 & 0.2 & 0.8 & 1 & 0 & \\
\hline 59 & 1.5 & 3 & 4 & 0 & 2 & 0.5 & $0.5^{\prime}$ & 0.8 & 0.2 & \\
\hline 60 & 3 & 4.5 & 2 & 0 & 0 & 0 & $1^{\prime}$ & 0.4 & 0.6 & \\
\hline 61 & 4.5 & 6 & 2 & 0 & 1 & 0.5 & $0.5^{\prime}$ & 0.4 & 0.6 & \\
\hline 62 & 6 & 7.5 & 1 & 0 & 0 & 0 & $1^{r}$ & 0.2 & 0.8 & \\
\hline 63 & 7.5 & 9 & 1 & 0 & 0 & 0 & $1^{7}$ & 0.2 & 0.8 & \\
\hline 64 & 9 & 10.5 & 1 & 0 & 0 & 0 & $1^{\prime \prime}$ & 0.2 & 0.8 & \\
\hline 65 & 10.5 & 12 & 1 & 0 & 0 & 0 & 17 & 0.2 & 0.8 & \\
\hline 66 & 12 & 13.5 & 1 & 0 & 0 & 0 & $1^{r}$ & 0.2 & 0.8 & \\
\hline 67 & 13.5 & 15 & 1 & 0 & 1 & 1 & $0^{\prime}$ & 0.2 & 0.8 & \\
\hline 68 & & & & & & & & & & \\
\hline
\end{tabular}

Fig. 8: Numerical Values of Survivorship Calculation of the Treatment Group

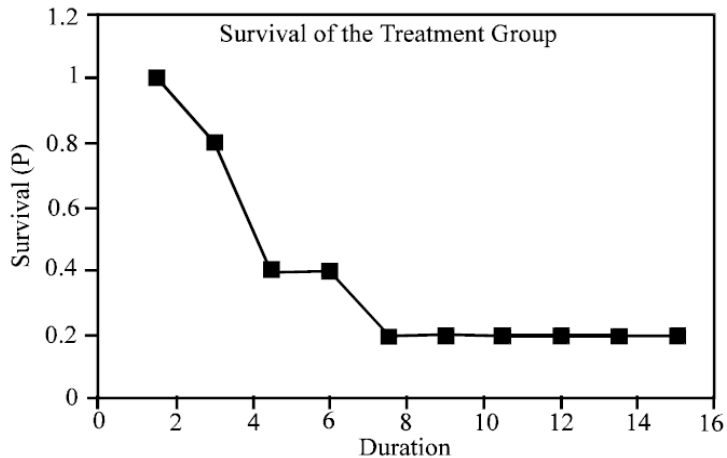

Fig. 9: Survival Chart of the Treatment Group

As is clear from the graph, at least 60 per cent of the subjects in the control group could still survive up to the $9^{\text {th }}$ period. Also about 25 percent of the individuals stayed in the job market for the whole observation period of 15 months.

If we are all interested in this group we can stop here. But usually, we would like to also measure the impact of an independent variable on the survivorship. It happens to be the college level pre-business courses in our case. We replicated all of our calculations for the treatment group in Fig. 7 through 9. Since the process is identical we will not repeat the discussion on calculations here.
A close inspection of Fig. 9 reveals that about 60 per cent of the individuals exited the current state by the $4^{\text {th }}$ period. In comparison to the control group, this is a much faster exit rate. That is, those who took the prebusiness classes while at high school to earn a prebusiness certificate tend to find jobs a lot faster than those who did not. Additionally, the percentage of those who stayed in the job market for the whole period is relatively less among the treatment group than the control group. Hence, we conclude that a pre-business certification earned by taking college level business classes while in high school makes finding a job after graduation easier with respect to those who failed to obtain that certificate.

Before concluding, I believe it would be worthwhile to mention that the hazard function and pdf can be easily incorporated into the Excel file generated above. In the interest of space, however, the Excel snapshots are not included here. For the hazard function and the pdf, all one has to do is to enter the following formula into Excel, respectively:

$$
\begin{aligned}
& h_{j} \frac{2 q_{j}}{r\left(1+p_{j}\right)} \\
& f_{j}=\frac{P_{j} q_{j}}{r}
\end{aligned}
$$


where all the variables are as defined before. All of the components of these computations are readily available in the Excel file already generated.

\section{CONCLUSION}

Duration analysis (also known as survival analysis besides quite a few other names) has found sympathetic audiences in engineering and medical research as well as several social sciences for a long time. Its history in economics and business is short by comparison, but arguably rich. In almost all sub-branches of economics and business we can find some application of survival analysis. Nevertheless, this toolbox has been avoided by the undergraduate Econometrics textbooks since it is considered an advanced topic beyond the possible grasp of students at this level. Given the perspective it can offer to students in formulating real life problems, I believe an introduction to this topic, however basic, ought to be made at the earliest stages of education to alert the students to these kinds of problems. Furthermore, practitioners, who may not have plenty of time to invest and venture in new methods of econometric analysis, too, should find the technique interesting for suitable cases and the way it is presented here easy to comprehend.

With mainly these two interest groups in mind, I worked out a simple Excel file which uses an artificially generated data set to introduce the reader to duration analysis. Without being bogged down with the theoretical jargon full of formulas, but still keeping the integrity of the scientific treatment of a topic, I show the calculations needed to generate life tables for two different groups and provide interpretation of the findings with the help of graphs. This provides a relatively complete presentation of the life table's analysis procedure in an easy to understand and apply manner. Needless to say that there are certain software packages which carry out these calculations with a point and click of a mouse, but my presentation opens up the black box for the student, who may proceed from here on with more sophisticated applications of the survival analysis.

\section{REFERENCES}

1. Hosmer, D.W. and S. Lemeshow, 1999. Applied Survival Analysis: Regression Modeling of Time to Event Data. New York: John Wiley and Sons, Inc.

2. Allison, P.D., 2001. Survival Analysis Using The SAS System: A Practical Guide, Cary, North Carolina: SAS Institute, Inc.

3. Hald, A., 1990. A History of Probability and Statistics and Their Applications Before 1750. New York: John Wiley and Sons, Inc.

4. Lancaster, T., 1997. The Econometric Analysis of Transition Data. Cambridge University Press.

5. Van den Berg, G.J., 2001. Duration Models: Specification, Identification and Multiple
Durations. In Handbook of Econometrics, vol. 5, chapter: 55, Amsterdam: North Holland. Eds.: Heckman, J.J. and E. Leamer.

6. Kiefer, N.M., 1988. Economic Duration Data and Hazard Functions. J. Economic Literature, 646-679.

7. Yamaguchi, K., 1991. Event History Analysis, Newbury Park: Sage.

8. Andersen, P.K., O. Borgan, R.D. Gill and N. Keiding, 1993. Statistical Models Based on Counting Processes, New York: Springer.

9. Nickel, S., 1979. Estimating the Probability of Leaving Unemployment. Econometrica, 47:12491266.

10. Lancaster, T., 1979. Econometric Methods for the Duration of Unemployment. Econometrica, 47: 939-956.

11. Heckman, J.J. and G. Borjas, 1980. Does Unemployment Cause Future Unemployment? Definitions, Questions and Answers from a Continuous Model of Heterogeneity and State Dependence. Econometrica, 47: 247-283.

12. Kennan, J.F., 1985. The Duration of Contract Strikes in US Manufacturing. J. Econometrics, 28: 5-28.

13. Mortensen, D.T., 1986. Job Search and Labor Market Analysis. In O. Ashenfelter and R. Layard, Eds., Handbook of Labor Economics, Amsterdam: North-Holland.

14. Bonnal, I., D. Fougere and A. Serandon, 1997. Evaluating the Impact of French Employment Policies on Individual Labor Market Histories. Review of Economic Studies, 64: 683-713.

15. Butler, J.S., K.H. Anderson and R.V. Burkhauser, 1989. Work and Health After Retirement: A Competing Risks Model With Semiparametric Unobserved Heterogeneity. The Review of Economics and Statistics, 46-53.

16. Meyer, B.D., 1990. Unemployment Insurance and Unemployment Spells. Econometrica 58: 757-82.

17. Kim, Y.W., 1990. The Influence of Health at Work: A Dynamic Analysis of the Timing of Job Exit and Disability Insurance Application, Ph.D. Thesis. Vanderbilt University.

18. Devine, T.J. and N.M. Kiefer, 1991. Empirical Labor Economics. Oxford: Oxford University Press.

19. Sahin, H., 1999. Applications of the Bivariate Interval Hazard and Autoregressive Conditional Duration (ACD) Model, Ph.D. Thesis. Vanderbilt University.

20. Bollens, J. and I. Nicaise, 1994. The MediumTerm Impact of Vocational Training on Employment and Unemployment Duration. Paper prepared for the European Association of Labor Economists Conference, Warsaw, September.

21. Cockx, B. and I. Bardoulat, 2000. Vocational Training: Does it speed up the Transition Rate out of Unemployment? Tinbergen Institute Discussion Papers, 00-01613. 
22. Cockx, B. and M. Dejemeppe, 2002. Do the Higher Educated Unemployed Crowd out the Lower Educated Ones in a Competition for Jobs? Université catholique de Louvain, Institut de Recherches Economiques et Sociales (IRES) Discussion Paper.

23. Sahin and Genc, 2003. A Risk of Combining Risks: An Application of a Bivariate Interval Hazard Model. Paper presented at the $83^{\text {rd }}$ Annual Meetings of Southwestern Economics Association in San Antonio.

24. Lillard, L.A., 1993. Simultaneous Equations for Hazards. J. Econometrics, 56: 189-217.

25. Lindstrom, D.P., 1996. Economic Opportunity in Mexico and return Migration from the United States. Demography, 33: 357-374.

26. Heckman, J.J. and J.R. Walker, 1990. The Relationship between Wages and Income and the Timing and Spacing of Births. Econometrica, 58: 1411-1441.

27. Fergusson, D.M., J.T. Horwood and F.T. Shannon, 1984. A Proportional Hazards Model of Family Breakdown. J. Marriage and the Family, 47: 539-549.

28. Vilcassim, N.J. and D.C. Jain, 1991. Modeling Purchase Timing and Brand Switching Behavior Incorporating Explanatory Variables and Unobserved Heterogeneity. J. Marketing Res., 28: 29-41.

29. Antonides, G., 1988. Scrapping a Durable Consumption Good. Erasmus Universiteit, Rotterdam.

30. Boizot, C., J.M. Robin and M. Visser, 1997. The Demand for Food Products: An Analysis of Interpurchase Times and Purchased Quantities. Working Paper, CREST, Paris.

31. Gönül, F. and K. Srinivasan, 1993. Consumer Purchase Behavior in a Frequently Bought Product Category: Estimation Issues and Managerial Insights From a Hazard Function Model With Heterogeneity. J. The American Statistical Association, 88: 1219-1227.

32. Fok, D., R. Paap and P.H. Franses, 2002. Modeling Dynamic Effects of Promotion on Interpurchase Times. Econometric Institute Report 289, Erasmus University Rotterdam, Econometric Institute.

33. Pakes, A. and M. Schankerman, 1984. The Rate of Obsolescence of Knowledge, Research Gestation Lags and the Private Rate of Return to Research Resources. In Z. Griliches, Ed., Patents, R and D and Productivity, Chicago: University of Chicago Press.

34. Anti Nilsen, O. and F. Schiantarelli, 1998. Zeros and Lumps in Investment: Empirical Evidence on Irreversibilities and Non-Convexities. Working Paper, University of Bergen, Bergen.

35. Ridder, G. and J.C. Van Ours, 2000. Fast Track or Failure: A Study of the Completion Rates of Graduate Students in Economics. CEPR Discussion Paper 2363.
36. Diebold, F.X. and G.D. Rudebusch, 1990. A Nonparametric Investigation of Duration Dependence in the American Business Cycle. J. Political Economy, 98: 596-616.

37. Ongena, S., D.C. Smith and D. Michalsen, 2000. Distressed relationships: lessons from the Norwegian banking crisis (1988-1991), Discussion Paper 13, Tilburg University, Center for Economic Research.

38. Hollifield, B., R. Miller, P. Sandås and J. Slive, 2002. Liquidity Supply and Demand in Limit Order Markets. CEPR Discussion Paper no. 3676. London, Center for Economic Policy Research.

39. Ongena, S. and D.C. Smith, 1999. The Duration of Bank Relationships. Mimeo, University of Florida.

40. Engel, R. and J. Russell, 1998. Autoregressive Conditional Duration: A New Model for Irregularly Spaced Transaction Data. Econometrica, 66:1127-1162.

41. Bhattacharjee, A., C. Higson, S. Holly and P. Kattuman, 2002. Macro Economic Instability and Business Exit: Determinants of Failures and Acquisitions of Large UK Firms. Cambridge Working Papers in Economics, Department of Applied Economics, University of Cambridge.

42. King, G., J. Alt, M. Laver and N. Burns, 1990. A Unified Model of Cabinet Dissolution in Parliamentary Democracies. American J. Political Sci., 34: 847-871.

43. Alt, J. and G. King, 1994. Transfers of Governmental Power: The Meaning of Time Dependence. Comparative Political Studies, 27:190-210.

44. Diermeir, D. and R.T. Stevenson, 1999. Cabinet Survival and Competing Risks. American J. Political Sci., 46: 200-247.

45. Horvath, W.J., 1968. A Statistical Model for the Duration of Wars and Strikes. Behavioral Sci., 13: 24.

46. Heckman, J.J. and B. Singer, 1984. A Method for Minimizing the Impact of the Distributional Assumptions in Econometric Models for Duration Data. Econometrica, 53: 271-320.

47. Ridder, G., 1990. The Non-Parametric Identification of Generalized Failure-Time Models. Review of Economic Studies, 167-182.

48. Kalbfleisch, J.D. and Ross L. Prentice, 1980. The Statistical Analysis of Failure Time Data. New York: John Wiley and Sons Inc.

49. Collett, D., 1994. Modeling Survival data in Medical Research. London: Chapman and Hall.

50. Cox, D.R. and D. Oakes, 1994. Analysis of Survival Data. London: Chapman and Hall.

51. Greene, W.H., 1993. Econometric Analysis. New York: Macmillan. 